\title{
Ask the Experts
}

Were Increased Closed Seclusions the Result of

a Reinforcer-Abolishing Effect?

\section{Alan Poling, Ph.D., BCBA-D \\ Western Michigan University}

In recent years, the motivating operation (MO) concept and the terms associated with it, including "reinforcer-abolishing effect" (Laraway, Snycerski, Michael, \& Poling, 2003), have been widely used in the behavior-analytic literature (Laraway, Snycerski, Olson, Becker, \& Poling, in press) and elsewhere (Lotfizadeh, Edwards, \& Poling, 2013). MOs are changes in the environment that alter the reinforcing effectiveness of designated classes of stimuli, such as food or water.

Abolishing operations (AOs) reduce reinforcing effectiveness, that is, they have a reinforcer-abolishing effect, whereas establishing operations (EOs) have a reinforcer-establishing effect and increase reinforcing effectiveness. With respect to the fascinating data reported by Ahrendt, Houlihan, and Buchanan, it is certainly plausible that poker chips served as effective conditioned reinforcers in a token economy system that engendered appropriate responding incompatible with the inappropriate responding that led to closed seclusions. Stickers, in contrast, were less effective conditioned reinforcers (or not effective at all), and inappropriate responding increased dramatically when they replaced tokens. If the terms are used loosely, the change from tokens to stickers could be viewed as an $\mathrm{AO}$ and the increase in closed seclusions as a reinforcer-abolishing effect. I would not use such language, however, for two reasons. The first is that no direct evidence of altered reinforcer effectiveness is provided. The second is that it's easy to confuse labels with explanation.
The primary value of the $\mathrm{MO}$ concept is that it focuses attention on specific operations (i.e., alterations of the environment) that produce changes in behavior indicative of altered reinforcer effectiveness (e.g., changes in rate of responding, speed of acquiring new behavior, choice, resistance to perturbation, or self-reported craving). Knowing the specific kinds of environmental changes that serve as AOs or EOs allows one to specify in advance the probable effects of such operations, hence to predict, control, and explain some aspects of behavior. Michael (e.g., 2007) delineated a number of operations that influence reinforcing effectiveness. Although the MO subtypes he described do not include some operations, such as providing certain kinds of verbal rules, that alter the reinforcing effectiveness of particular stimuli (Lotfizadeh et al., 2013), his analysis does provide a basis for understanding and explaining some aspects of "motivation."

In contrast, labeling the switch from tokens to stickers as an " $\mathrm{AO}$ " and the increase in undesired responding, 
hence closed seclusions, that resulted from the change a "reinforcer-abolishing effect" does nothing to explain that effect or to predict and control behavior in other situations. It is highly unlikely that shifting from one putative conditioned reinforcer to another characteristically generates undesirable behavior. Instead, it appears that in the case described by Ahrendt et al. the participants' experiences with tokens and stickers, and perhaps with other, related aspects of their environment, differenced in ways that engendered dissimilar levels of inappropriate responding when tokens and stickers were delivered under the token economy system. Isolating those experiential differences and explaining how, in terms of established behavioral principles, those differences accounted for the dissimilar levels of closed seclusions across conditions is the only way to understand what actually happened. Perusing archival records and conducting interviews with participants and staff might provide clues to the relevant variables. Call them what you will, those variables were clearly powerful and clinically significant, and are worth isolating if possible.

\section{References}

Laraway, S., Snycerski, S., Michael, J., \& Poling, A. (2003). Motivating operations and terms to describe them: Some further refinements. Journal of Applied Behavior Analysis, 36, 407-414.

Laraway, S., Snycerski, S., Olson, R., Becker, B., \& Poling, A. (in press). The motivating operations concept: Current status and a critical response. Psychological Record.

Lotfizadeh, A. D., Edwards, T. L., \& Poling, A. (2013). Motivating operations in the Journal of Organizational Behavior Management. Review and discussion of relevant articles. Journal of Organizational Behavior Management, accepted for publication pending revision.

Michael, J. L. (2007). Motivating operations. In Cooper, J. C., Heron, T. L. \& Heward, W. L. (Eds.), Applied behavior analysis (2nd ed., pp. 374-391). Upper Saddle River, NJ: Pearson Education.

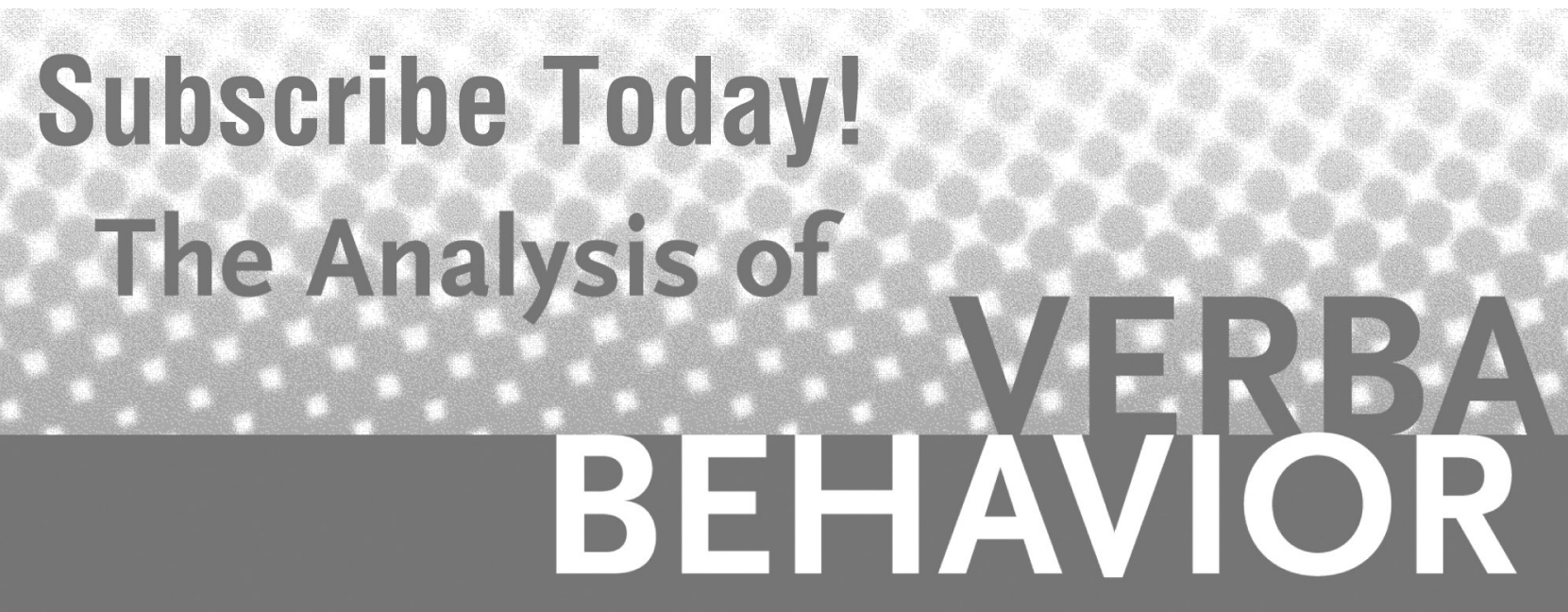

- The original publication of experimental or theoretical papers relevant to a behavioral analysis of verbal behavior.

- Keep up-to-date on key topics such as elementary verbal operants, multiple control, rule-governed behavior, epistemology, language acquisition, pedagogy, verbal behavior research methodology, and others.

- This annual publication is just $\$ 43$ for ABAI members!

Visit the ABAI website at www.abainternational.org/journals/theanalysis-of-verbal-behavior.aspx to order your subscription from the online store today! 